\title{
Review Article \\ Gravity Effects of Curing Angle on Laminated Composite Structures: A Review on Novel Study
}

\author{
T. T. T. Jennise, ${ }^{1}$ M. Y. Yuhazri, ${ }^{1}$ Haeryip Sihombing, ${ }^{1}$ \\ S. H. Yahaya, ${ }^{1}$ Umar Nirmal, ${ }^{2}$ and M. M. H. Megat Ahmad ${ }^{3}$ \\ ${ }^{1}$ Faculty of Manufacturing Engineering, Universiti Teknikal Malaysia Melaka, Hang Tuah Jaya, \\ 76100 Durian Tunggal, Melaka, Malaysia \\ ${ }^{2}$ Faculty of Engineering and Technology, Multimedia University, Jalan Ayer Keroh Lama, 75450 Melaka, Malaysia \\ ${ }^{3}$ Faculty of Engineering, National Defence University of Malaysia, Kem Sungai Besi, 57000 Kuala Lumpur, Malaysia
}

Correspondence should be addressed to T. T. T. Jennise; tanjennise@yahoo.com

Received 16 May 2013; Accepted 20 August 2013

Academic Editor: Tao Zhang

Copyright (C) 2013 T. T. T. Jennise et al. This is an open access article distributed under the Creative Commons Attribution License, which permits unrestricted use, distribution, and reproduction in any medium, provided the original work is properly cited.

\begin{abstract}
Composites manufactured by small and medium industries/entrepreneurs (SMI/E) are conventionally cured in the horizontal position. Hence, the confined space restricts optimum productivity. Besides, SMI/E is unable to allocate high budget for high-end technology such as autoclave and vacuum mechanical oven which limits the development of SMI/E as a result of high capital cost. Through a series of literature review, the review confirmed that there is no similar scientific study has been conducted. Consequently, the review is carried out to facilitate the investigation of the feasibility of a gravity cured glass fiber laminated thermosetting composites via vacuum bagging at angle position from horizontal $\left(0^{\circ}\right)$ to vertical $\left(90^{\circ}\right)$ to enhance the curing space required.
\end{abstract}

\section{Introduction}

Composite are not new such as polymer matrix composites (PMC) that have been highly introduced and recommended for applications that required high specific stiffness and strength, dimensional stability, low density, and admirable corrosion resistance $[1,2]$. That is why fiber-reinforced PMC are able to offer multiple advantages compared to the monolithic materials, for instance, ceramics, plastics, and metals [3]. Composites are commonly and widely applied in the sector of aerospace, shipping, and railway structures [4]. Glass fiber is a common reinforcement used in composites especially in fiber reinforced plastics [5-8] and has high potential in terms of its amazing properties and industrial demand that attracts the researches to carry out investigations [9-11]. Meanwhile epoxy is a good candidate as the matrix in the composite. Various researchers such as those in [12-14] had carried out their investigations using epoxy due to its outstanding thermal and mechanical properties such as high temperature performance and high bonding strength $[15,16]$.
Curing is an important process which may determine the properties of the composite material. A proper curing system can further enhance the performance. Conventionally, composites are cured via thermal treatment by transferring energy via conduction, convection, and radiation $[17,18]$. The raw materials in the composites, namely, reinforcement and matrix, are of the low thermal conductivity and thus requires longer curing duration. During the curing process, the formation of bonding is an exothermic reaction which produces an internal heat and slowly dissipates out $[19,20]$.

In this research, an investigation is to be carried out to look into the effect of gravity of laminated composites cured at various angles ranging from $10^{\circ}-90^{\circ}$ by verifying the mechanical properties such as tensile, flexural, and hardness. Furthermore, the physical properties such as density, water absorption and swelling are to be carried out since the physical properties could be the detrimental factors to the mechanical performance. On top of that, the aim of the study is also to find out whether there is any gravity effect on the composites when the samples were cured at angled position ranging from 
$10^{\circ}-90^{\circ}$ with different resin. It is interesting to observe how the curing process would affect the properties if different resins of varying viscosities are used.

\section{Thermoset as Matrix Material}

Epoxy and polyester are two extensively used resins in the composites' field for various commercial applications $[16,21-$ 25]. They can be easily available and involve simple handling procedures.

2.1. Epoxy Resin. According to Broomfield et al. [26], epoxy resin is a class of versatile polymer material which is characterized by the oxirane that is present within the molecular structure. Epoxy can be categorized as an industrial thermosetting resin and widely applied in engineering fields such as aerospace industry and electric and electronic sectors [16, 27]. Meanwhile, epoxy is unique in its properties such as low shrinkage, high strength, high resistance to environmental degradation, and good elevated temperature service capability [28]. Besides, epoxy shrinks less compared to other matrices and can be cured at low temperature between $5^{\circ}$ and $150^{\circ} \mathrm{C}$ [29].

In addition, another favourable characteristic of epoxy is having low viscosity during its uncured state which eases the processing during fabrication without having to use high pressure equipment [30]. Besides, the composites that can be applied for structural applications requiring high strength and low weight are those with epoxy resin reinforced with glass fiber [31].

Thermosetting polymers are harder and stronger than thermoplastics [32]. Besides that, thermosetting polymers are insoluble in the organic solvents compared to thermoplastics. The thermosetting polymers form three-dimensional network structure due to the cross-linking of strong covalent bonds during moulding. Therefore, thermosetting polymers only degrade but will not turn soft even after prolonged heating. On the other hand, thermoplastics will become soft as a result of easily broken secondary bonds when heat is applied. Figure 1 shows the chemical formula of the epoxy resin.

2.2. Unsaturated Polyester Resin. Unsaturated polyester is a rigid and low reactivity matrix and ever since has always been a common and famous matrix in PMC $[24,33,34]$. Unsaturated polyester is conveniently applied for hand lay-up fabricated products for its room temperature cure capability with the help of $1-3 \%$ of methyl ethyl ketone peroxide (MEKP) as a hardener [35-37], transparency and low pressure moulding capability [33].

Research by Pohlak et al. [38] and Yuhazri et al. [39] proved that the ratio of polyester and MEKP catalyst is manipulated from 0.8 to $2.0 \%$ can vividly show the significance in curing time and its mechanical properties such as modulus of elasticity and tensile strength. However, the high MEKP content (more than 5\%) in the composite leads to shorter curing time but creates more defects such as shrinkage, wrinkles, and over isothermal heat cracks and also reduces mechanical properties. Another investigation revealed

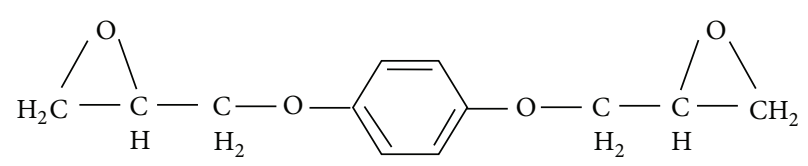

Figure 1: Chemical formula of the epoxy resin 1,3-bis(2,3-epoxypropoxy)-benzene [41].

$$
\mathrm{OC} \longrightarrow \mathrm{R}_{1}-\mathrm{CO}-\mathrm{O}-\mathrm{R}_{2}-\mathrm{O}
$$

FIGURE 2: Chemical formula for unsaturated polyester.

that 12 hours of curing period is not sufficient to obtain its desired composite properties, while 36 hours cure time does not further influence the performance [40]. On the contrary, 24 hours at room temperature is just a perfect match of curing. Figure 2 shows the chemical formula of the unsaturated polyester.

Unsaturated polyester is cured by free radical mechanisms when exposed to light with the addition of MEKP [24]. Barbero [29] investigated that polyester has good UV resistance to structural degradation which can survive exposure to more than 30 years in service. Table 1 shows the density, viscosity, advantages, and disadvantages of epoxy and unsaturated polyester.

During the curing of thermosetting composite, the exothermic reaction will take place. As for the same amount of mass of a fluid, the density and viscosity will decrease slightly when the temperature is increased. Sih et al. [42] had studied the heating changes of the physical and chemical state of the resin. At the same time found a decrement in the resin viscosity in the composite due to heating. The composite may further be heated till the resin starts to flow. Additional heat applied by increasing the temperature can lead to polymerization and cross-linking in the structure. Raising the temperature no doubt can decrease the viscosity of the matrix. However, it can cause matrix degradation and thermal residual stress to the composites especially of those thick laminates due to the exothermic reaction during curing $[43,44]$.

The viscosity of the resin plays important role in wetting the fibers during the impregnation. Resins with lower viscosities tend to have more complete wetting. Imbalance wetting of fibers will not have desired mechanical bonding between the fibers and matrix [45]. Either resin starvation or resin rich area is not good. According to Hoa [46], it may be a disadvantage to have more resin rich regions as these locations are weak and act as areas for crack to nucleate when under load. The lower the viscosity of a matrix, the larger and thicker a composite structure can be manufactured [29].

\section{Recent Researches on Laminated Composites Using Glass Fibers}

Glass fiber is the most commonly used fibers in the polymer fiber-reinforced composites due to several factors such as low cost, high tensile strength, and good insulating properties [25, 47]. As revealed by Sawant et al. [48], surface coating on glass 
TABLE 1: Density, viscosity, advantages, and disadvantages of epoxy and unsaturated polyester.

\begin{tabular}{|c|c|c|}
\hline Matrix & Epoxy & Unsaturated polyester \\
\hline \multirow{3}{*}{ Density $\left(\mathrm{kg} / \mathrm{m}^{3}\right)$} & $1100[12]$ & $1100-1400[49]$ \\
\hline & $1100-1350[50]$ & $1200[51]$ \\
\hline & $1200-1300[49]$ & $1400[50]$ \\
\hline \multirow{3}{*}{ Viscosity $(\mathrm{Pa} \cdot \mathrm{s})$ at $25^{\circ} \mathrm{C}$} & $0.15[52,53]$ & $0.4[54]$ \\
\hline & $\begin{array}{c}0.3[53] \\
9-17[55]\end{array}$ & $0.764\left(20^{\circ} \mathrm{C}\right)[56]$ \\
\hline & $10-15[57]$ & $0.3-0.4[58]$ \\
\hline \multirow{3}{*}{ Advantage } & Lower shrinkage $[15,28]$ & Low viscosity $[59,60]$ \\
\hline & Lower residual stress $[28]$ & Short curing time $[59,60]$ \\
\hline & $\begin{array}{l}\text { Wide selection of curing agent with good control in the degree of } \\
\text { cross-linking }[15,28]\end{array}$ & Low cost $[59,60]$ \\
\hline \multirow{2}{*}{ Disadvantage } & Brittle $[28,30]$ & Poor resistance to acids [60] \\
\hline & $\begin{array}{l}\text { Poor resistance to crack propagation/low fracture toughness } \\
\qquad[15,61]\end{array}$ & Low fiber/matrix bond strength $[60]$ \\
\hline
\end{tabular}

fiber can increase the alkali resistance and wearing resistance. In a recent investigation by Furtos et al. [6], the mechanical properties such as flexural strength and Young's modulus can be improved when unidirectional glass fiber bundles were used instead of woven glass fiber, though woven glass fiber has more favourable handling procedures. Besides, the mechanical properties can be further developed by postpolymerization curing treatment and adding content of glass fiber.

3.1. Fiber Glass/Epoxy. Pihtili [31] reported in his study that the glass fiber-epoxy resin composites generally showed lower wear than glass fiber-polyester resin composites as the wear occurs in the matrix instead of in the reinforcement when tested under 0.39 and $0.557 \mathrm{~m} / \mathrm{s}$ speeds at two different loads of $5 \mathrm{~N}$ and $10 \mathrm{~N}$. A study by Ramirez et al. [2] found that the strength of epoxy decreased by two folds when exposed to water for 800 hours at $40^{\circ} \mathrm{C}$ under flexural testing. On top of the finding, a conclusion of E-glass fiber can be degraded by long term water exposure and worsened at elevated temperature. It is because the chemical nature of the polymer matrix which is highly attracted to water that brings forth of plasticization in the composites. The secondary bonding is broken which can cause the reduction of Young's modulus and glass transition temperature.

In an analysis by Rao et al. [62], the tensile and interlaminar shear strength of a composite structure cured via microwave is better than that cured via thermal. Beside that, microwave curing technique also offers uniformity of cure and substantial energy saving during the cure process. On the other hand, woven glass fiber/epoxy composites laminated at $\left[0 / 90^{\circ}\right]_{7}$ have high potential to replace a steel body cover in an automobile with better performance such as 2.9 times impact resistance, 3.35 times stiffness and, desirability factors 1.8 times compared to steel [7].

E-glass fiber will experience irreversible loss in terms of tensile strength though at moderately low temperature and short heating times. The composites will undergo a drastic decrement in strength when the temperature is increased to above $200^{\circ} \mathrm{C}$ [63]. When the temperature reaches $600^{\circ} \mathrm{C}$, the strength of the glass fiber is only found to have a few percent of its original strength. The mechanical properties, for instance, tensile strength, flexural strength and interlaminar shear strength of the glass fiber-epoxy composite, are diminished if the glass fiber is pretreated with $\mathrm{HCl}$ acid prior to silanization [64].

3.2. Fiber Glass/Polyester. From tensile and bending test, the mechanical results of glass fiber-polyester composite such as elastic modulus and tensile strength obtained are optimum if the specimens are fabricated at $40^{\circ} \mathrm{C}$ with $1 \%$ of the initiator or $20^{\circ} \mathrm{C}$ with $2 \%$ of initiator [56]. In accordance with the increase in the amount of initiator, the reaction rate increases while the gelation time decreases. It is realized that microwave energy can be applied to shorten the curing time [17]. The mechanical properties of a glass fiber-reinforced polyester composite that cure with microwave energy are comparable with those cured for 10 days of self-curing.

From the long term water immersion experiment carried out by [1], it is found that the composite made up of laminated woven E-glass/polyester samples demonstrated highest resistance to water proven with a low initial rate and absorption rate due to lower void presence and higher glass volume fraction. It is further explained that water is not allowed to be absorbed through the cracks as a result of swollen matrix in water immersion for duration of 30 months. Another water absorption test was conducted, it concluded that diminishing in the mechanical properties is caused by the decrease in its glass transition temperature [65]. When there is high moisture content in the matrix and/or interface, radial stresses and fiber-matrix adhesion tend to decrease rapidly.

\section{Curing}

The investigation of new processing technique often results in improved material performance or greater benefits. Conventional curing of heating thermosetting resin in the oven is 


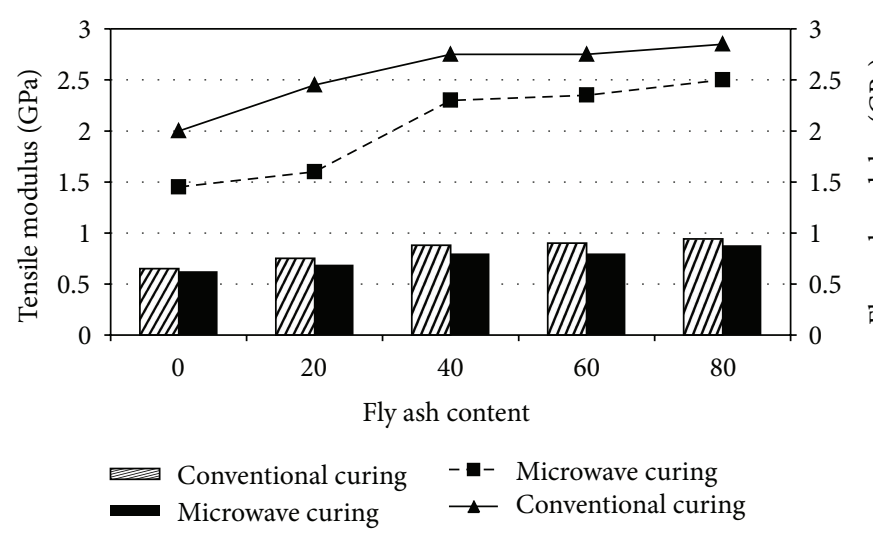

(a) Tensile and flexural moduli against fly ash content

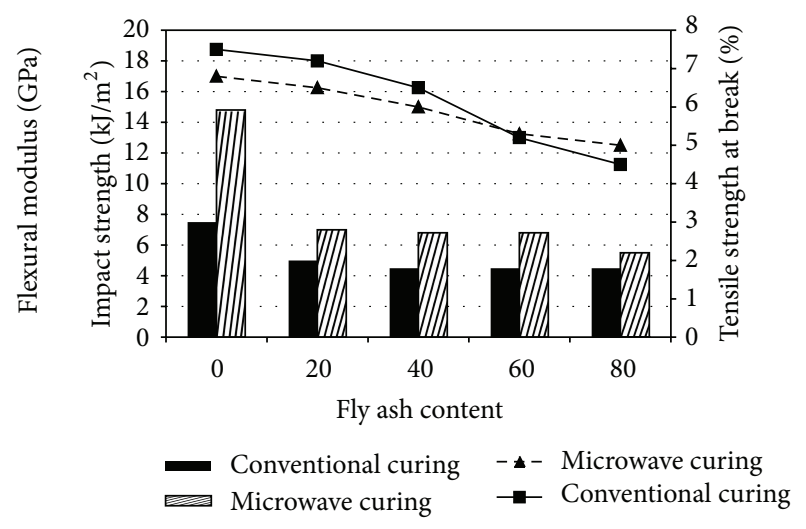

(b) Impact strength and tensile strength at break against fly ash content (modified from [66])

FIGURE 3: Effect of fly ash content on tensile, flexural moduli, and impact and tensile strength for conventional and microwave cured of fly ash/epoxy composite.

a direct application of thermal energy from heaters. Besides the traditional method of thermal curing, composites can be cured by ultraviolet (UV), microwave, and electron beam (EB) since they have shorter curing time at room temperature, lower cost, and more environmentally friendly $[9,67$, 68]. When the isothermal curing of thermoset starts, the initial reaction rate is dependent on the temperature and degree of cure of the conditions [69]. Figure 3 shows the effect of fly ash content on tensile, flexural moduli, and impact and tensile strength for conventional and microwave cured of fly ash/epoxy composite: (a) tensile and flexural moduli against fly ash content and (b) impact strength and tensile strength at break against fly ash content. From Figure 3, it can be concluded that fly ash samples showed better tensile and flexural moduli when conventional curing is carried out. On the other hand, results of impact strength and tensile strength tend to be higher for microwave curing rather than conventional curing.

UV curing technique refers to the formation of crosslinking and polymerization of a viscous liquid resin to the gel formed and finally in the cured stage of solid resin via radiation. The cross-linking will only be initiated upon the exposure to the UV light $[66,70]$. From the research carried out by Abulizi et al. [9], it is reported that in situ UV curing method is likely be the alternative fabrication technique for conventional thermal curing process for large and thick composite parts. On the other hand, it is concluded that the mechanical properties such as tensile and flexural tests of 10-minute UVcured composites are comparable to the 4-hour $90^{\circ}$ thermal postcured treatment [70], while the 24 hours room temperature cure composite exhibited the lowest performance. Figure 4 reveals the in situ manufacturing process.

Epoxy resin cured by conventional oven-curing takes prolonged duration $[17,62,68,71]$. It is because the heat diffuses from the surface to the core of the material depending on the heat transfer rate. As a result, the curing time increases. In contrast, the entire composite is heated simultaneously if cured via microwave [18]. On the other hand, the microwaves

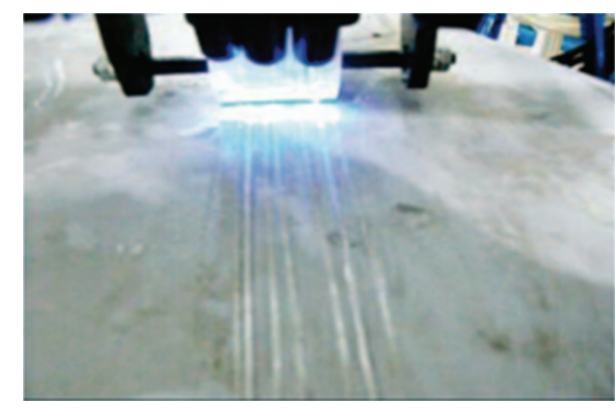

FIGURE 4: In situ UV curing manufacturing process [9].

curing method can also be applied to preheat to shorten the final curing time besides allowing more uniform and efficient cure $[68,71]$. Higher polymerization rate, improved mechanical and physical properties can be achieved in certain epoxies if a pulsed microwave is used. Microwave curing is preferred over conventional heating for a reduced curing time and increased glass transition temperature. As such, the temperature has to be controlled to avoid unexpected damage in the composites. Figure 5 shows the schematic drawing of microwave equipment.

As said by Vautard et al. [67], EB curing technique is an energy efficient and environmental friendly process compared to thermal heating curing. Lesser energy consumption and curing cycle of several minutes are among the advantages. EB curing is suitable for large and complex structures such as for aerospace applications. EB curing involves high energy electrons rather than heat to initiate the polymerization process to enable the cross-linking to take place. Composites cured by EB irradiation tend to have higher performance compared to those done via thermal treatment such as better fracture stress and bending fracture strain $[14,67]$. Figure 6 shows the thermal history of the resin during the EB curing of the composite laminate. 


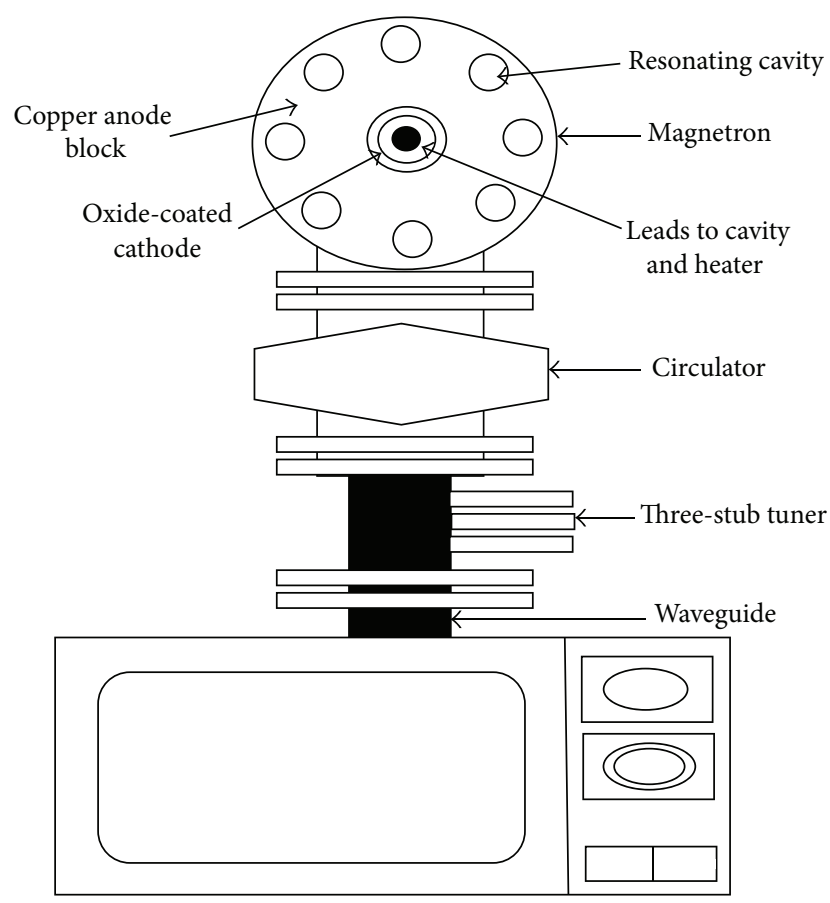

FIGURE 5: Schematic drawing of microwave equipment (modified from [68]).

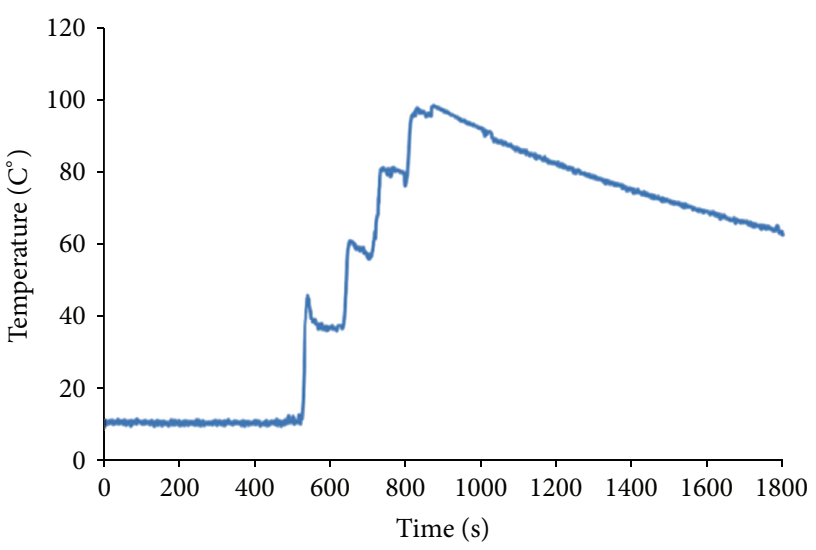

Figure 6: Thermal history of the resin during the electron beam (EB) curing of the composite laminate [67].

\section{Theory of Fluid Flow}

According to Cengel and Cimbala [60], an internal resistance that develops within a fluid to mobility is called the viscosity. The higher the viscosity a liquid possesses, the harder the liquid to flow. When two mediums come into contact with each other, a friction force exists at the surface of the contact to resist the motion. At the same time, the gravitational force that exists at all times tends to work against the friction force to pull the uncured resin in the composites towards one direction especially when an angle is applied during the curing process. The gravity force may cause the uncured resin such as the epoxy and unsaturated polyester to flow downwards making the resin more saturated at the bottom of the laminated composite if the composite is tilted to cure at an angle position demonstrating the effect of the density of filler in metal matrix composite (MMC) but not in PMC [72].

In reality, the higher gravity force is likely to act on the composite if a higher angle position is arranged. However, the effect of gravity force on the uncured resin in the laminated composite is considered quite limited. It is because a vacuum pump is connected to the composite to suck the resin at all four sides to work against the gravitational force that tend to make the resin flow downwards. At the same time, the pump sucks out trapped air within the sealed bag so that a vacuum medium is prepared which allows the composite to expose to the atmospheric pressure. As the composite now is being compressed, it discourages the flow of liquid resin. In addition, the surface tension that exists between the matrix and reinforcement will tend to resist the fluid flow. The idea behind the research can be more understandable based on Figure 7(a) that describes the glass fiber composite structure that is being cured at horizontal position $0^{\circ}$ while Figure $7(\mathrm{~b})$ cured at an angle between $10^{\circ}$ and $80^{\circ}$ with an increment of $10^{\circ}$ each to determine whether the viscous resin will be deposited towards the bottom part of the composite region due to gravitational effect, and Figure 7 (c) cured at vertical position $90^{\circ}$.

The pressure in a fluid increases with depth in vertical position in a gravitational field. Therefore, more resin tends to rest on the deeper layers. That is why the flow of resin is anisotropic. The basic equation denotes the flow of the liquid resin and in the case of porous reinforcement mat is called the Navier-Stokes equation as

$$
\rho \frac{D u}{D t}=-\nabla P+\mu \nabla^{2} u+\rho g=\nabla P+\mu \nabla^{2} u,
$$

where $\rho$ is the density, $u$ is the velocity of the fluid, $t$ is the time, $P$ is the pressure, $\mu$ is the viscosity of the resin, and $g$ is the acceleration due to the gravitational effect.

However, (1) can be further simplified due to low flow rate by eliminating nonlinear momentum effects contained in the material derivatives. Therefore, the modification of NavierStokes is now called the Stokes flow as shown in (2)

$$
0=-\nabla P+\mu \nabla^{2} u
$$

The reinforcement is permeable to the matrix while the mechanical properties can be affected by the permeability. This kind of fluid flow is governed by Darcy's law. Darcy's law states that the rate of volume discharge through a porous solid medium is related to the pressure gradient applied to the solid and the hydraulic permeability coefficient $k$. Darcy's law is also known as seepage velocity as

$$
u_{i}=-\left(\frac{k_{i j}}{\mu}\right) \cdot\left(\nabla P_{i}\right),
$$

where $u_{i}$ is the volume average velocity of the fluid, $k_{i j}$ is the permeability tensor for the preformance, $\mu$ is the viscosity of the resin, and $P$ is the pressure in the resin.

Under Darcy's law, there will be no viscous resin flow when no pressure gradient is present over a distance as illustrated in Figure 7(a). On the other hand, when the composite 

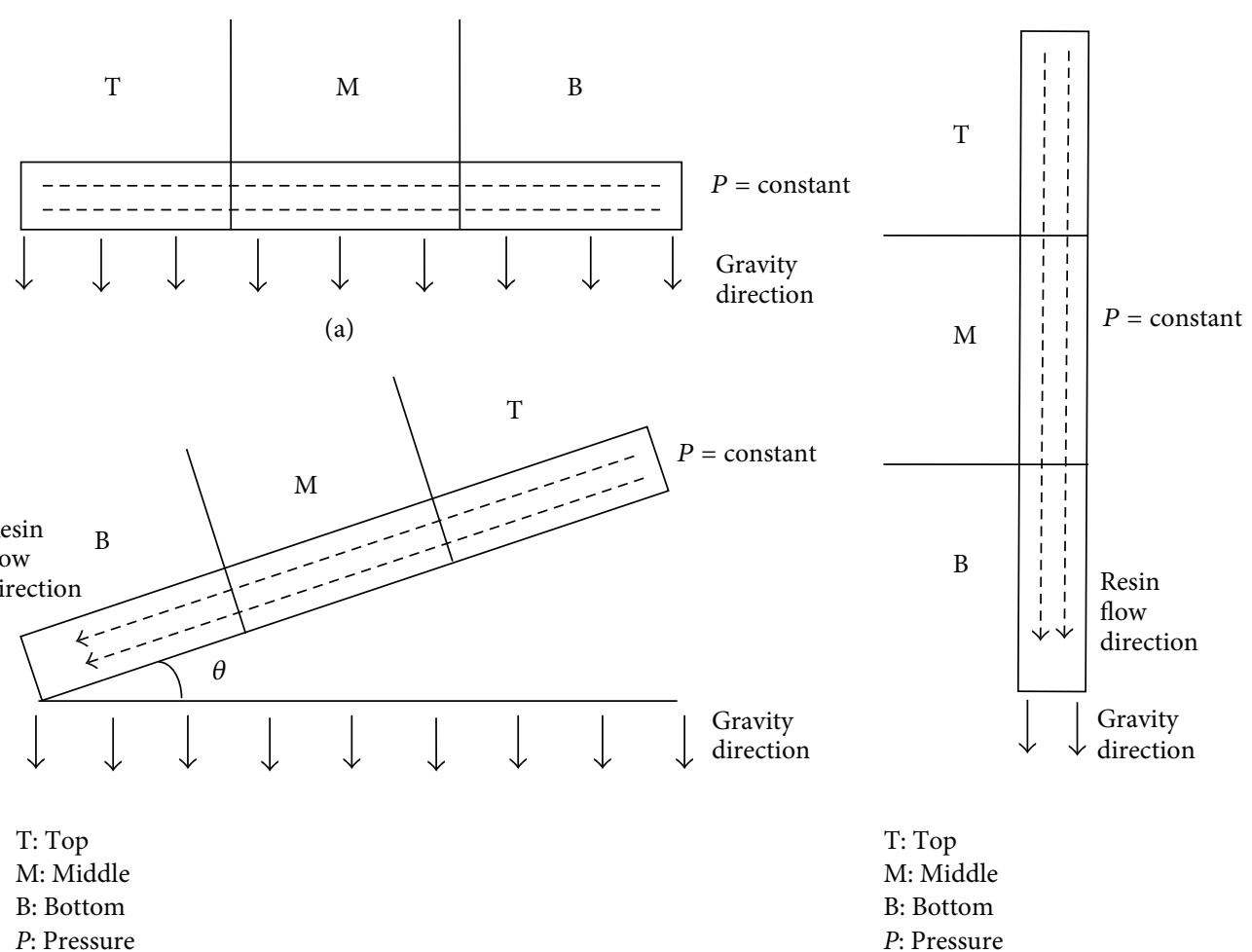

(b)

(c)

FIGURE 7: Laminated composite cured at (a) $0^{\circ}$, (b) $10^{\circ}-80^{\circ}$, and (c) $90^{\circ}$.

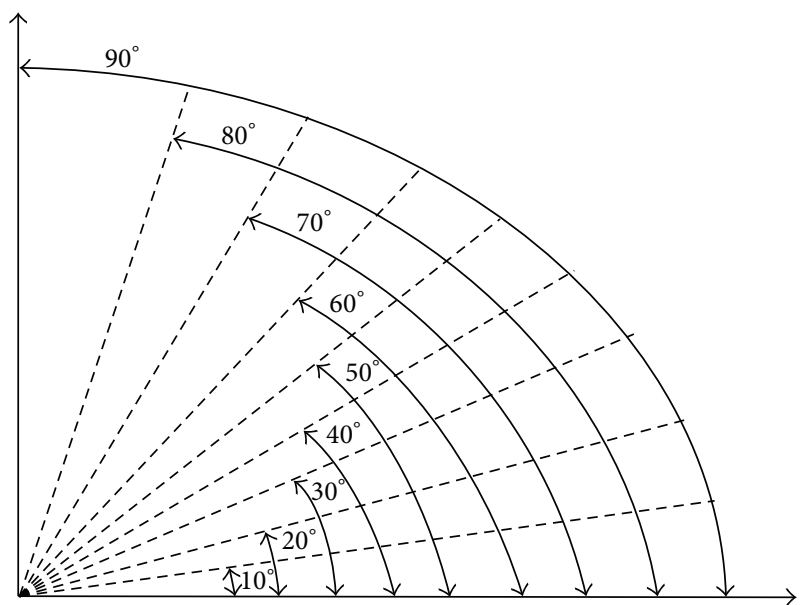

FIGURE 8: Curing angles of laminated composite.

structure is tilted to an angle as seen in Figure 7(b), the gravity effect experienced by the higher region away from the horizontal surface tends to have higher pressure. As a result, the viscous resin flow will occur from high pressure towards low pressure due to a pressure gradient. In Figure 7(c), the composite is cured at vertical position; thus, an investigation is to be carried out to check on whether resin starvation will occur.

The fibers are presumed to have a constant thickness such as incompressible and nondeformable porous fibers with isotropic permeability [43]. On the other hand, the resin region is presumed to be isothermal and Newtonian with an estimated steady viscosity. These assumptions are not firmly valid and occur in applications but do generate an approximate analytic solution.

\section{Future Planning of Methodology or Development}

In this research, wet lay-up and vacuum bagging techniques are adopted to fabricate the four-ply laminated composite structure. A mould set that has been coated with gel coat will be prepared. Sealant tape is placed to surround the edge of the mould. At the inner sides of the sealant tape, the silicon spiral pipe is arranged to allow the excess resin to be sucked out from the composite once the vacuum pump is turned on.

The stack of glass fiber is arranged in the orientation of $[0 / 90]_{2}$. After that, ply-by-ply of the glass fiber sized of approximate $420 \mathrm{~mm} \times 460 \mathrm{~mm}$ will be placed on the mould by applying the liquid resin (epoxy and unsaturated polyester) by hand with the ratio of glass fiber/resin of $60: 40$ by weight. Beforehand, the MEKP hardener is added to the resin approximately $1-3 \%$ by weight for the polymerization and cross-linking to occur between the fiber and resin during curing. Next, the release fabric or peel ply, perforated film, breather cloth, and the nylon netting are laid over the stacked laminated composite in the correct sequence. 


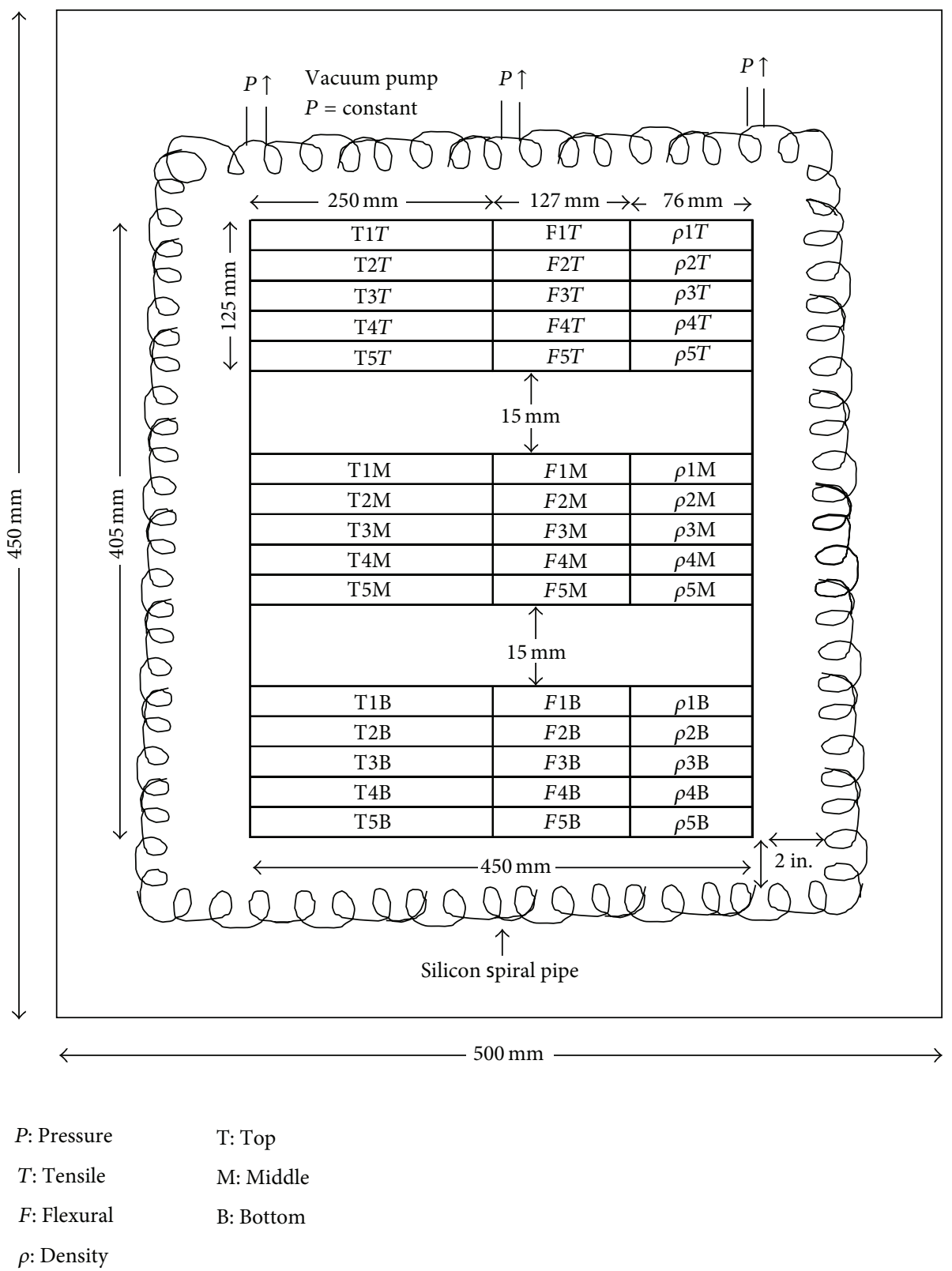

FIGURE 9: Estimated dimension for the composite samples.

Lastly, the vacuum bag is spread over around the stacked laminated and mould supported by the sealant tape to provide an airtight seal to allow atmospheric pressure to act on it. The mould is placed in a position of either horizontal or in the designated angle $\left(10^{\circ}-90^{\circ}\right)$ before switching on the vacuum pump for an hour to vacuum out the trapped air at the same time assuring no leakage occurs. Then, the laminated composite is left to cure at room temperature still attached to the chosen angle for around 24 hours before removing from the mould and discarding the bagging materials. Figure 8 is the proposed curing angles for the laminated composites.

Each of the composite structures is divided into top, middle, and bottom regions equally. The composites are prepared to cut into the sample size according to the testing planned to carry out. The tests under mechanical test are tensile (ASTM
D 3039), flexural (ASTM D 790) and hardness (ASTM D 2240) while physical test are water and swelling (ASTM D 570) and density (ASTM D 792). Figure 9 shows the estimated dimension for the laminated composite for each of curing angles. In the specimen, the gap of approximated $15 \mathrm{~cm}$ is prepared to differentiate between the top, middle, and bottom regions. It is done to provide a clear distinction of whether the effect of matrix in these three regions would give different mechanical and physical properties when matrix of different viscosity is used.

\section{Conclusion}

Besides using the various curing method such as ultraviolet, microwave, and electron beam technique, a study regarding 
an angle position curing method is investigated. This research is considered as a novel study since no researchers have carried out investigations concerning the gravity effect on the laminated composite during curing. In order to verify whether mechanical and physical properties of the laminated composite via gravity curing are affected by the flow of resin at the tilted angle position, the laminated cured composite that is cured at $0^{\circ}$ is set as the benchmark for other samples that is cured at an angle between $10^{\circ}$ and $90^{\circ}$ with an increment of $10^{\circ}$ each.

\section{Acknowledgments}

The authors would like to thank the Faculty of Manufacturing Engineering in Universiti Teknikal Malaysia Melaka (UTeM) and its financial support under Grant FRGS/2012/FKP/TK01/03/1/F00133.

\section{References}

[1] K. Berketis and D. Tzetzis, "Long-term water immersion ageing characteristics of GFRP composites," Journal of Materials Science, vol. 44, no. 13, pp. 3578-3588, 2009.

[2] F. A. Ramirez, L. A. Carlsson, and B. A. Acha, "Evaluation of water degradation of vinylester and epoxy matrix composites by single fiber and composite tests," Journal of Materials Science, vol. 43, no. 15, pp. 5230-5242, 2008.

[3] D. Chandramohan and K. A. Marimuthu, "Review on natural fibers," International Journal of Research and Reviews in Applied Sciences, vol. 8, pp. 194-206, 2011.

[4] C. Atas and O. Sayman, "An overall view on impact response of woven fabric composite plates," Composite Structures, vol. 82, no. 3, pp. 336-345, 2008.

[5] T. H. Almusallam, Y. A. Al-Salloum, S. H. Alsayed, S. El-Gamal, and M. Aqel, "Tensile properties degradation of glass fiber-reinforced polymer bars embedded in concrete under severe laboratory and field environmental conditions," Journal of Composite Materials, vol. 47, no. 4, pp. 393-407, 2012.

[6] G. Furtos, L. Silaghi-Dumitrescu, M. Moldovan, B. Baldea, R. Trusca, and C. Prejmerean, "Influence of filler/reinforcing agent and post-curing on the flexural properties of woven and unidirectional glass fiber-reinforced composites," Journal of Materials Science, vol. 47, no. 7, pp. 3305-3314, 2012.

[7] M. Golzar and M. Poorzeinolabedin, "Prototype fabrication of a composite automobile body based on integrated structure," International Journal of Advanced Manufacturing Technology, vol. 49, no. 9-12, pp. 1037-1045, 2010.

[8] A. Zolfaghari, A. H. Behravesh, A. Adli, and M. T. Sarabi, "Continuous glass fiber reinforced wood plastic composite in extrusion process: feasibility and processing," Journal of Reinforced Plastics and Composites, vol. 32, no. 1, pp. 52-60, 2012.

[9] D. Abulizi, Y. Duan, D. Li, and B. Lu, "A new method for glass-fiber reinforced composites manufacturing: automated fiber placement with in-situ UV curing," in Proceedings of the IEEE International Symposium on Assembly and Manufacturing (ISAM '11), pp. 1-4, Tampere, Finland, May 2011.

[10] F. Avalos, G. Pincheira, J. Inostroza, and P. Flores, "Material parameter identification for vacuum infusion manufactured components," International Journal of Material Forming, vol. 3, no. 1, pp. 579-582, 2010.
[11] E. H. Harkati, A. Bezazi, M. Guenfoud, and F. Scarpa, "Stacking layer sequence effects for glass fibre/epoxy resin cross-ply laminates," Strength of Materials, vol. 39, no. 3, pp. 320-330, 2007.

[12] G. Agarwal, A. Patnaik, and R. K. Sharma, "Parametric optimization of three-body abrasive wear behavior of bidirectional and short kevlar fiber reinforced epoxy composites," International Journal of Engineering Research and Applications, vol. 2, no. 6, pp. 1148-1167, 2012.

[13] M. P. Cavatorta, "A comparative study of the fatigue and postfatigue behavior of carbon-glass/epoxy hybrid RTM and hand lay-up composites," Journal of Materials Science, vol. 42, no. 20, pp. 8636-8644, 2007.

[14] A. Mizutani and Y. Nishi, "Improved strength in carbon fiber reinforced plastics due after electron beam irradiation," Materials Transactions, vol. 44, no. 9, pp. 1857-1860, 2003.

[15] H. Wang, Y. Zhang, L. Zhu, Z. Du, B. Zhang, and Y. Zhang, "Curing behaviors and kinetics of epoxy resins with a series of biphenyl curing agents having different methylene units," Thermochimica Acta, vol. 521, no. 1-2, pp. 18-25, 2011.

[16] G. Zhang, J. Cheng, L. Shi, X. Lin, and J. Zhang, "Study on curing kinetics of diallyl-bearing epoxy resin using sulfur as curing agent," Thermochimica Acta, vol. 538, pp. 36-42, 2012.

[17] A. M. Visco, L. Calabrese, P. Cianciafara, L. Bonaccorsi, and E. Proverbio, "Fiber reinforced polyester resins polymerized by microwave source," Journal of Materials Engineering and Performance, vol. 16, no. 6, pp. 792-799, 2007.

[18] M. R. Mousavi and M. Rafizadeh, "Microwave cross-linking of LDPE: experimental modelling of gel content by taguchi method and optimum processing conditions," Iranian Polymer Journal, vol. 16, no. 10, pp. 681-689, 2007.

[19] G. F. Abdelal, A. Robotham, and W. Cantwell, "Autoclave cure simulation of composite structures applying implicit and explicit FE techniques," International Journal of Mechanics and Materials in Design, vol. 9, no. 1, pp. 55-63, 2012.

[20] A. Z. Ahmad Mujahid, M. A. Nurul Aliaa, A. Norashida, A. G. Balamurugan, M. N. Norazman, and A. Shohaimi, "Experimental modal analysis (EMA) on coconut coir fibre reinforced composite," Global Engineers \& Technologists Review, vol. 1, no. 1, pp. 15-20, 2011.

[21] N. A. Anthony, "Evaluation of mechanical properties of polyester matrix reinforced with bamboo fibre for the production of low strength building products," International Journal of Engineering and Applied Sciences, vol. 2, no. 2, pp. 57-66, 2013.

[22] X. Haijun, L. Lulu, C. Guangtao, Z. Na, F. Yiming, and H. Weirong, "Impact response and damage evolution of triaxial braided carbon/epoxy composites. Part I: ballistic impact testing," Textile Research Journal, 2013.

[23] A. Kara, A. Tasdemirci, and M. Guden, "Modeling quasi-static and high strain rate deformation and failure behavior of a $( \pm 45)$ symmetric e-glass/polyester composite under compressive loading," Materials \& Design, vol. 49, pp. 566-574, 2013.

[24] B. Janković, "The kinetic analysis of isothermal curing reaction of an unsaturated polyester resin: estimation of the density distribution function of the apparent activation energy," Chemical Engineering Journal, vol. 162, no. 1, pp. 331-340, 2010.

[25] T. P. Philippidis and A. E. Antoniou, "A progressive damage FEA model for glass/epoxy shell structures," Journal of Composite Materials, vol. 47, no. 5, pp. 623-637, 2013.

[26] L. M. Broomfield, R. M. Sebastián, J. Marquet, and R. Schönfeld, "Ambient temperature polymerisation of oxiranes initiated by the novel $\mathrm{MSbF}_{6} / \mathrm{H}_{2} \mathrm{O}$ co-initiator system," Polymer, vol. 53, no. 25, pp. 5632-5640, 2012. 
[27] J. Kandpal, S. B. Yadaw, and A. K. Nagpal, "Mechanical properties of multifunctional epoxy resin /glass fiber reinforced composites modified with poly (ether-imide)," Advanced Materials Letters, vol. 4, no. 3, pp. 241-249, 2013.

[28] D. Ratna, Epoxy Composites: Impact Resistance and Flame Retardancy, vol. 16, 2005.

[29] E. J. Barbero, Introduction to Composite Materials Design, CRC Press, New York, NY, USA, 2011.

[30] J. V. Y. Ruban, G. S. Mon, and V. D. Roy, "Mechanical and thermal studies of unsaturated polyester-toughened epoxy composites filled with amine-functionalized nanosilica," Applied Nanoscience, vol. 3, no. 1, pp. 7-12, 2012.

[31] H. Pihtili, "An experimental investigation of wear of glass fibreepoxy resin and glass fibre-polyester resin composite materials," European Polymer Journal, vol. 45, no. 1, pp. 149-154, 2009.

[32] M. A. Jail, H. J. Sawant, and A. P. Kulkarni, Applied Science-I, Technical Publications, Pune, India, 2009.

[33] N. S. M. El-Tayeb, "A study on the potential of sugarcane fibers/polyester composite for tribological applications," Wear, vol. 265, no. 1-2, pp. 223-235, 2008.

[34] S. Sangthong, T. Pongprayoon, and N. Yanumet, "Mechanical property improvement of unsaturated polyester composite reinforced with admicellar-treated sisal fibers," Composites A, vol. 40, no. 6-7, pp. 687-694, 2009.

[35] R. M. Ali, "Diffusion of salt water and alkaline solutions in polyester reinforced by glass fibers," Journal of Engineering Materials and Technology, vol. 30, no. 10, pp. 1749-1756, 2012.

[36] S. R. Chauhan, "Effect of microsize particulates on tribological characteristics of vinylester composites under dry and lubricated conditions," Materials Science and Engineering, vol. 2, no. 1, pp. 2-7, 2013.

[37] V. A. Prabu, V. Manikandan, M. Uthayakumar, and S. Kalirasu, "Investigations on the mechanical properties of red mud filled sisal and banana fiber reinforced polyester composites," Materials Physics and Mechanics, vol. 15, pp. 173-179, 2012.

[38] M. Pohlak, J. Majak, K. Karjust, and R. Küttner, "Multi-criteria optimization of large composite parts," Composite Structures, vol. 92, no. 9, pp. 2146-2152, 2010.

[39] M. Y. Yuhazri, P. T. Phongsakorn, and H. Sihombing, "A comparison process between vacuum infusion and hand lay-up method toward kenaf/polyester composite," International Journal of Basic and Applied Science, vol. 10, no. 3, pp. 63-66, 2010.

[40] P. S. Jain and A. A. Shaikh, "An investigation of mechanical behaviour of resin with varying parameters of curing," International Journal of Emerging Technology and Advanced Engineering, vol. 2, no. 5, pp. 231-234, 2012.

[41] N. Iwamoto, M. M. F. Yuen, and H. Fan, Molecular Modeling and Multiscaling Issues for Electronic Material Applications, Springer, London, UK, 2012.

[42] G. C. Sih, A. Carpinteri, and G. Surace, Advanced Technology for Design and Fabrication of Composite Materials and Structure, Kluwer Academic, Dodrecht, The Netherlands, 1995.

[43] D. C. Blest, B. R. Duffy, S. McKee, and A. K. Zulkifle, "Curing simulation of thermoset composites," Composites A, vol. 30, no. 11, pp. 1289-1309, 1999.

[44] S. M. Lee, Handbook of Composite Reinforcements, Wiley-VCH, San Francisco, Calif, USA, 1993.

[45] J. Ahmad, Machining of Polymer Matrix Composites, Springer, 2009.

[46] S. V. Hoa, Principles of the Manufacturing of Composite Materials, DEStech, Lancaster, Pa, USA, 2009.
[47] M. M. Jadhav and P. V. Gunjavate, "Optimization of buckling load for glass fiber composite laminate by using ansys," International Journal of Advanced Engineering Research and Studies, vol. 2, no. 1, pp. 144-147, 2012.

[48] S. G. Sawant, A. B. Sawant, and M. B. Kumthekar, "Strengthening of R.C.C. beam- using different glass fiber," International Journal of Inventive Engineering and Sciences, vol. 1, no. 2, pp. 18, 2013.

[49] K. K. Chawla, Composite Materials: Science and Engineering, Materials Research and Engineering, Springer, New York, NY, USA, 2012.

[50] J. R. Vinson and R. L. Sierakowski, The Behavior of Structures Composed of Composite Materials, Kluwer Academic, Dodrecht, The Netherlands, 2008.

[51] S. B. Brahim and R. B. Cheikh, "Influence of fibre orientation and volume fraction on the tensile properties of unidirectional Alfa-polyester composite," Composites Science and Technology, vol. 67, no. 1, pp. 140-147, 2007.

[52] Y. Choe, S.-J. Chen, and E. S. Kim, "High fidelity loud microspeaker based on PZT bimorph diaphragm," in Proceedings of the NSTI Nanotechnology Conference and Expo, vol. 2, pp. 316-319, Anaheim, Calif, USA, June 2010.

[53] P. Sethu, H. Yu, P. Grodzinski, and C. H. Mastrangelo, "Fabrication of genetic analysis microsystems using plastic microcasting," in Proceedings of the Technical Digest, IEEE Solid-State Sensor and Actuator Workshop, pp. 175-179, Hilton Head Island, SC, USA, June 2000.

[54] R. Sakin, I. Ay, and R. Yaman, "An investigation of bending fatigue behavior for glass-fiber reinforced polyester composite materials," Materials and Design, vol. 29, no. 1, pp. 212-217, 2008.

[55] R. P. Patel and J. A. Chaudhari, "Material applications of novel interacting blends having S-triazine containing unsaturated polyesters and epoxy resin residues," International Journal of ChemTech Research, vol. 4, no. 2, pp. 572-577, 2012.

[56] N. Belloul, A. Ahmed-benyahia, A. Serier, and N. Ouali, "Effect of temperature and initiator on glass fibre/unsaturated polyester composite: cross-linking, mechanical properties," Damage and Fracture Mechanics, pp. 497-504, 2009.

[57] J. Stabik, A. Dybowska, M. Szczepanik, and Ł. Suchoń, "Viscosity measurements of epoxy resin filled with ferrite powders," Archives of Materials Science and Engineering, vol. 38, no. 1, pp. 34-40, 2009.

[58] R. Ollier, E. Rodriguez, and V. Alvarez, "Unsaturated polyester/bentonite nanocomposites: influence of clay modification on final performance," Composites A, vol. 48, pp. 137-143, 2013.

[59] A. Alan, A. Baker, and S. Dutton, Composite Materials For Aircraft Structures, AIAA, Washington, DC, USA, 2004.

[60] Y. A. Cengel and J. M. Cimbala, Fluid Mechanics Fundamentals and Applications, McGraw-Hill, Singapore, 2010.

[61] D. Roşu, C. N. Caşcaval, F. Mustaţă, and C. Ciobanu, "Cure kinetics of epoxy resins studied by non-isothermal DSC data," Thermochimica Acta, vol. 383, no. 1-2, pp. 119-127, 2002.

[62] R. M. V. G. K. Rao, S. Rao, and B. K. Sridhara, "Studies on tensile and interlaminar shear strength properties of thermally cured and microwave cured glass-epoxy composites," Journal of Reinforced Plastics and Composites, vol. 25, no. 7, pp. 783-795, 2006.

[63] S. Feih, K. Manatpon, Z. Mathys, A. G. Gibson, and A. P. Mouritz, "Strength degradation of glass fibers at high temperatures," Journal of Materials Science, vol. 44, no. 2, pp. 392-400, 2009.

[64] K. Sever, M. Sarikanat, Y. Seki, V. Cecen, and I. H. Tavman, "Effects of fiber surface treatments on mechanical properties of 
epoxy composites reinforced with glass fabric," Journal of Materials Science, vol. 43, no. 13, pp. 4666-4672, 2008.

[65] J. I. Cauich-Cupul, E. Pérez-Pacheco, A. Valadez-González, and P. J. Herrera-Franco, "Effect of moisture absorption on the micromechanical behavior of carbon fiber/epoxy matrix composites," Journal of Materials Science, vol. 46, no. 20, pp. 66646672, 2011.

[66] J. Xia, Y. Xu, J. Lin, and B. Hu, "UV-induced polymerization of urushiol without photoinitiator," Progress in Organic Coatings, vol. 61, no. 1, pp. 7-10, 2008.

[67] F. Vautard, P. Fioux, L. Vidal, J. Schultz, M. Nardin, and B. Defoort, "Influence of the carbon fiber surface properties on interfacial adhesion in carbon fiber-acrylate composites cured by electron beam," Composites A, vol. 42, no. 7, pp. 859-867, 2011.

[68] K. D. V. P. Yarlagadda and S.-H. Hsu, "Experimental studies on comparison of microwave curing and thermal curing of epoxy resins used for alternative mould materials," Journal of Materials Processing Technology, vol. 155-156, pp. 1532-1538, 2004.

[69] I. Fraga, S. Montserrat, and J. M. Hutchinson, "Vitrification during the isothermal cure of thermosets part I. An investigation using TOPEM, a new temperature modulated," Journal of Thermal Analysis and Calorimetry, vol. 91, no. 3, pp. 687-695, 2008.

[70] P. Compston, J. Schiemer, and A. Cvetanovska, "Mechanical properties and styrene emission levels of a UV-cured glassfibre/vinylester composite," Composite Structures, vol. 86, no. 13, pp. 22-26, 2008.

[71] T. Chaowasakoo and N. Sombatsompop, "Mechanical and morphological properties of fly ash/epoxy composites using conventional thermal and microwave curing methods," Composites Science and Technology, vol. 67, no. 11-12, pp. 2282-2291, 2007.

[72] R. Zagórski and J. Śleziona, "Influence of thermal boundary condition on casting process of metal matrix composite," Archives of Materials Science and Engineering, vol. 42, no. 1, pp. 53-61, 2010. 

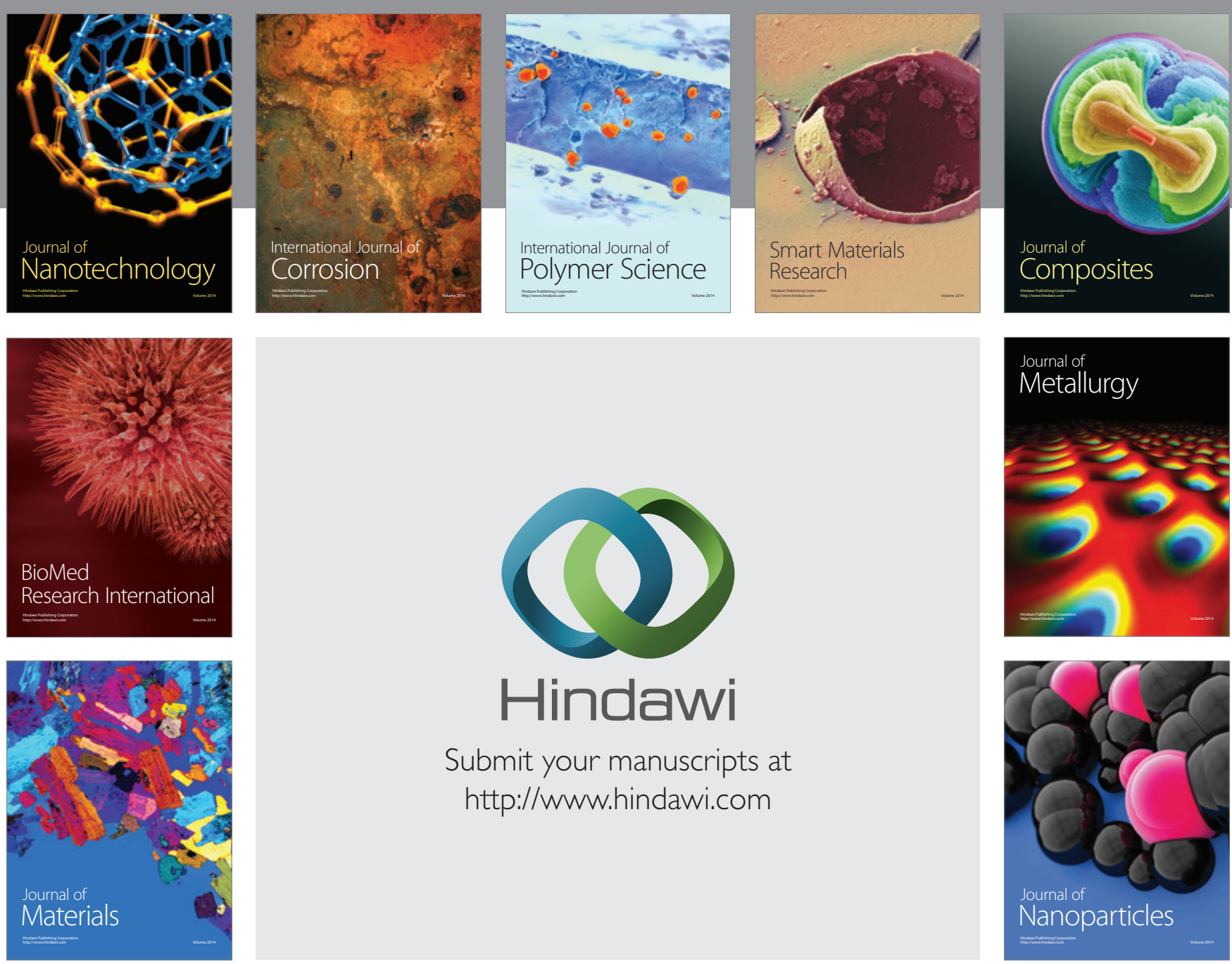

Submit your manuscripts at http://www.hindawi.com
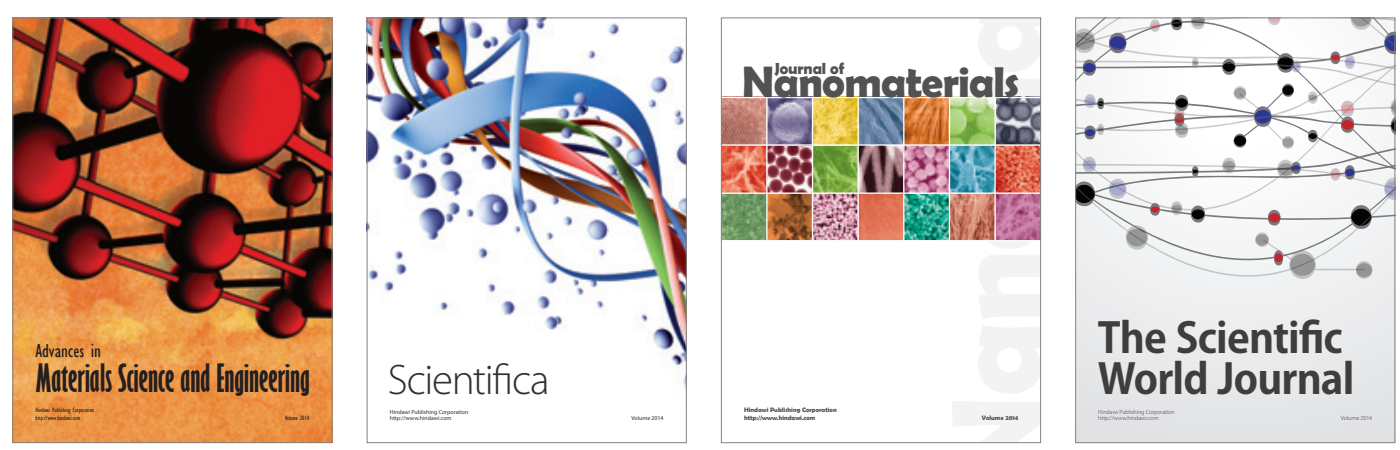

\section{The Scientific World Journal}
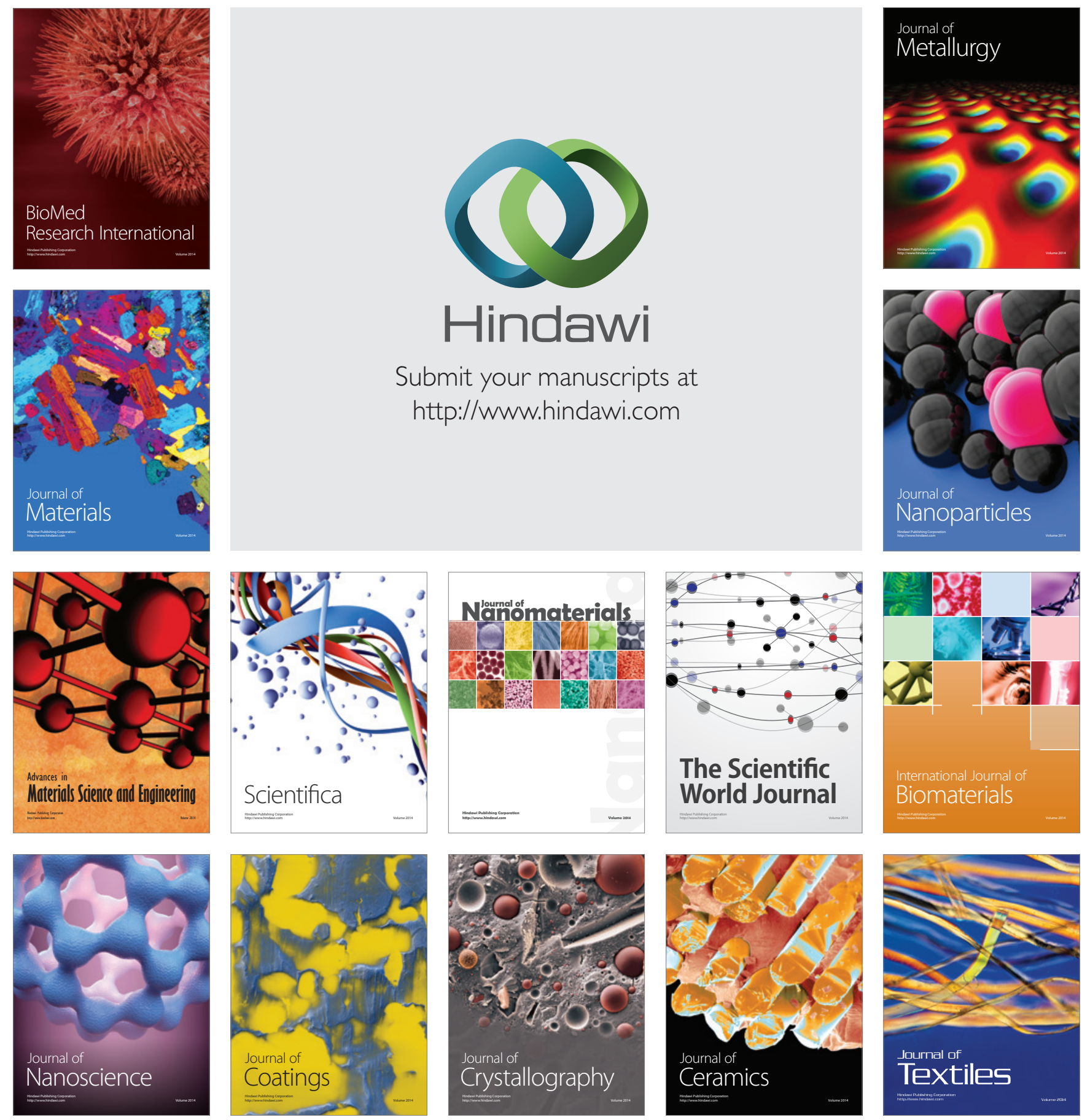